\section{EVIDENCE FOR EFFICACY OF OFF-PUMP CORONARY ARTERY BYPASS SURGERY: FACTS AND FADS \\ To the Editor:}

We recently read the reply to the Editor by Benedetto and associates, ${ }^{1}$ highlighting fundamental issues concerning meta-analyses. Interestingly, in an attempt to justify that metaanalyses of randomized controlled trials (RCTs) are the gold standard evidence to address controversial issues, they knowingly or unknowingly claim that "no RCT has ever confirmed the benefits of beating-heart coronary surgery implied by observational studies." ${ }^{1}$ Unfortunately, this claim from learned researchers like Benedetto and associates is contrary to the current best available evidence. ${ }^{2}$

Off-pump coronary artery bypass (OPCAB) surgery, since its resurgence in the early 1990s, has remained a highly scrutinized technique. The past decade was an era of trials and tribulations for OPCAB with more than 100 RCTs, over 300 observational studies, 60 propensity score analyses, and same number of metaanalyses of RCTs, as well as observational and propensity matched studies verifying every aspect and outcome of OPCAB. There is overwhelming evidence from both meta-analyses of RCTs as well as propensity score analyses to confirm safety and efficacy of $\mathrm{OPCAB}^{2,3}$ The majority of these RCTs and meta-analyses have shown that outcomes of OPCAB are either comparable or superior to on-pump coronary artery bypass surgery. ${ }^{2,3}$ In fact, $\mathrm{OPCAB}$ is associated with reductions in the risks for stroke $(50 \%)$, atrial fibrillation $(30 \%)$, wound infection $(48 \%)$, and acute kidney injury $(70 \%)$. $\mathrm{OPCAB}$ also reduces transfusion and inotrope requirements, ventilation time, intensive care unit and hospital stays, and in-hospital and 1-year direct costs. $^{2,3}$

There is no denying the fact that, whereas there is abundant evidence in favor of $\mathrm{OPCAB}$, there is also evidence that fails to show convincing benefits of OPCAB. ${ }^{4}$ In view of the conflicting evidence, there is a need for the cardiac surgical community to call for a forum and make specific recommendations. If it is agreed that the evidence is against OPCAB, then those performing such procedures should stop because they are affecting the quality of care of thousands of patients worldwide. ${ }^{5}$ If, on the other hand, it is agreed that the evidence for benefit of OPCAB is conclusive, then the implications are of a different order. However, until a verdict is reached, as responsible researchers and physicians it is important that we adopt an unbiased approach to analyze the available information's content for consistency, coherence, and clarity, thereby differentiating facts from fads.

\section{Shahzad G. Raja, MRCS, FRCSEd (C-Th) \\ Mohamed Amrani, PhD, FETCS Department of Cardiac Surgery Harefield Hospital London, United Kingdom}

\section{References}

1. Benedetto U, Angeloni E, Sinatra R. Reply to the Editor. J Thorac Cardiovasc Surg. 2010;139: 1670-1.

2. Raja SG, Berg GA. Outcomes of off-pump coronary artery bypass surgery: current best available evidence. Indian Heart J. 2007;59:15-27.

3. Patel NN, Angelini GD. Off-pump coronary artery bypass grafting: for the many or the few? J Thorac Cardiovasc Surg. 2010;140:951-3.e1.

4. Shroyer AL, Grover FL, Hattler B, Collins JF, McDonald GO, Kozora E, et al. Veterans Affairs Randomized On/Off Bypass (ROOBY) Study Group. N Engl J Med. 2009;361:1827-37.

5. Ascione R, Angelini GD. Off-pump versus conventional coronary artery bypass grafting: randomized studies. J Thorac Cardiovasc Surg. 2004;127: 300-1.

$$
\text { doi:10.1016/j.jtcvs.2011.04.046 }
$$

\section{IF WE ARE UNCRITICAL, WE SHALL ALWAYS FIND WHAT WE WANT \\ To the Editor:}

We thank Raja and associates for their comments on our recent letter to
Editor. ${ }^{1}$ In that letter, we observed that in observational studies comparing radial artery versus saphenous vein graft, the better patency rate observed for radial artery is surely biased by native vessel quality. Randomization avoids this important limitation. We stated that the dangerous effect of selection bias has also emerged in observational studies reporting beating-heart bypass advantages over on-pump surgery, which were not confirmed in randomized controlled trials. ${ }^{2}$ Apparently, Raja and associates did not like the latter statement.

However, this is not a personal point of view but a fact that every physician may read in a widely quoted international cardiovascular journal. ${ }^{2}$ It is obvious that in surgical series, beating-heart bypass has been preferentially adopted when good quality target vessels were present. This aspect has heavily biased results in retrospective analysis even when propensity analysis was adopted.

Results coming from randomized controlled trials that compare not similar but "exactly" the same patients reached the following conclusions as reported in widely quoted journals:

- No significant difference between off-pump and on-pump coronary artery bypass grafting in the rate of the 30-day composite outcome; the overall rate of graft patency was lower in the off-pump group than in the on-pump group. ${ }^{3}$

- No major differences in 30-day outcomes in high-risk patients randomized to off-pump versus on-pump coronary bypass surgery: the Best Bypass Surgery Trial. ${ }^{4}$

- Coronary artery bypass grafting performed off-pump had lower overall graft patency rate than onpump. Thirty-day complications, neuropsychologic functioning, and 1 -year clinical and functional outcomes were not statistically different between the 2 techniques. ${ }^{5}$ 